\title{
A Teoria das Pessoas de Teixeira de Freitas: entre Individualismo e Humanismo
}

\author{
eflexandxe dos Pantos Gunha
}

Bacharel em Direito e Licenciando em Filosofia pela UFPel e Mestrando em Direito Civil pelo PPGD/UFRGS.

\section{Introdução}

1ongo e atribulado processo codificatório civil brasileiro teve seu grande impulso, indiscutivelmente, através da obra de AUGUSTO TEIXEIRA DE FREITAS. Grande sistematizador, o Esboço de Código Civil por ele confeccionado, entre 1859 e 1867, é um dos mais importantes textos da literatura jurídica nacional, além de maior e mais importante influência do Código Civil vigente.

Extremamente rigoroso quanto ao método, constrói TEIXEIRA DE FREITAS todo o sistema de seu Esboço sobre a bipartição dos direitos em pessoais e reais. Conseqüentemente, o conceito de pessoa por ele adotado é capital para a compreensão de seu pensamento, e, portanto, das bases teóricas sobre as quais se assenta a legislação civil brasileira.

1. Ensaio originalmente apresentado, sob a forma de comunicação, quando do VI Congresso Brasileiro de Filosofia, promovido pelo Instituto Brasileiro de Filosofia e pela Faculdade
de Direito do Largo de São Francisco (USP), em 06 de setembro de 1999. 
No que tange à teoria das pessoas, a concepção mais geralmente aceita é a de que o individualismo kantiano, e a dogmática a partir deste desenvolvida por SAVIGNY, teriam sido a maior influência recebida pelo Esboço. O objetivo do presente ensaio é o de questionar esse entendimento, através de um estudo comparativo entre a teoria das pessoas liberal-individualista do século XIX e a contemporânea teoria da personalidade, a partir do qual se possa buscar situar teoricamente a compreensão de TEIXEIRA DE FREITAS acerca da questão.

Para tanto, iniciarei por uma análise da teoria das pessoas oitocentista, em especial de seu caráter individualista e patrimonialista, bem como da teoria da personalidade (I), para, em um segundo momento, construir, a partir do estudo do Esboço, a posição de TEIXEIRA DE FREITAS sobre o problema (II).

I - A teoria das pessoas e a teoria da personalidade: individualismo,

patrimonialismo e humanismo na dogmática civilística

A teoria das pessoas encontra-se geneticamente vinculada à histórica luta do homem pela garantia de sua liberdade indi-

vidual frente ao arbítrio do outro. ${ }^{2}$ Tem, portanto, em sua origem mesma, um forte componente individualista.

Para LAFER, ${ }^{3}$ a emergência, no campo do Direito, do individualismo, é o resultado de um longo processo histórico, que tem sua origem na filosofia estóica e cristã que, por pregar a prevalência da vida contemplativa sobre a atividade política, o que era necessário à salvação do Homem, acabou por inverter a prioridade, até então atribuída pela filosofia grega clássica, à pólis sobre o indivíduo. Desse longo e lento processo histórico de cerca de dois mil anos, que infelizmente não poderei abordar detidamente, resultará, a partir do nominalismo, a redução praticamente total da filosofia à epistemologia. ${ }^{4} \mathrm{O}$ antropocentrismo faz com que a possibilidade do conhecimento passe a ser a preocupação fundamental dos filósofos.

Não por acaso, é na Idade Média que os conceitos de "pessoa" e de "ser humano" começam a tornar-se coincidentes. Antes de São Tomás de Aquino, considerava-se as coisas como podendo ser dotadas de capacidade jurídica, e, até que os jusnaturalistas espanhóis da Escola de Salamanca fossem chamados a resolver a questão do status jurídico das populações nativas da América, sequer se havia cunhado a idéia de que todos os seres humanos são pessoas.

2. Cf., entre outros, MESSINETTI, Davide. Personalità (diritti della), p. 358; LARENZ, Karl. Derecho justo: fundamentos de ética juridica, p. 58; e LOCKE, John. Two treatises of government, p. 306.

3. Cf. LAFER, Celso. A reconstrução dos direitos humanos: um diálogo com o pensamento de Hannah Arendt, pp. 118 e ss.

4. Sobre as relaçōes entre o nominalismo e a filosofia do Direito do iluminismo, ver ALVES, Gláucia Corrêa Retamozo Barcellos ALVES. Do nominalismo ao direito modemo: uma leitura de Michel Villey.

5. Cf. HATTENHAUER, Hans. Conceptos fundamentales del Derecho civil, pp. 14 e ss.
No entanto, a partir do desenvolvimento, por GRÓCIO, do conceito de direito subjetivo - o que, como ressalta VILLEY, ${ }^{6}$ apenas foi possível em virtude dessa mesma virada filosófica -, o conceito de pessoa será cada vez mais subsumido no de sujeito de direito. Por isso, KANT chegará a definir "pessoa", na Metafísica dos costumes, como sendo o sujeito cujos atos podem ser-lhe imputados. ${ }^{7}$ É sobre esse sujeito de direito, necessariamente um ser humano, ${ }^{8}$ que está baseada a teoria das pessoas de SAVIGNY, que vê a pessoa como mero elemento da teoria da relação jurídica. $^{9}$

A expansão das idéias de SAVIGNY será determinante para que os estudos sobre a pessoa, ao longo do século XIX, restrinjam-se à capacidade jurídica. $\mathrm{O}$ que importará à dogmática civilística oitocentista será a necessidade de operar tecnicamente o conceito de pessoa enquanto elemento da relação jurídica. Assim sendo, o "humano" na pessoa será relegado ao segundo plano pelo "técnico".

Mais profundas foram as conseqüências da associação do conceito oitocentista de pessoa àquilo que MESSINETTI denomina como sendo a "lógica proprietária" dos juristas do século XIX. ${ }^{10}$ Uma vez que a possibilidade de aquisição da propriedade era tida, na filosofia política Iluminista,

6. Cf. VILLEY, Michel. La genèse du droit subjectif chez Guillaume d'Occa",

7. Cf. HATTENHAUER, Hans. Op. cit., pp. 18 e ss.

8. Cf. KANT, Immanuel. Métaphysique des moeurs, vol. 2, p. 269.

9. Cf. HATTENHAUER, Hans. Op. cit., loc. cit.

10. Cf. MESSINETTI, Davide. Op. cit., pp. 356 e ss.

11. AUBRY ET RAU, Traité de Droit Civil français d'après la méthode de Zachariae. Tomo IX.

12. Cf. HATTENHAUER, Hans. Op. cit., pp. 22 e ss. como um dos mais fortes componentes da liberdade individual, a metodologia civilista tendia a pensar todo o Direito civil desde esse instituto. Estendida à teoria das pessoas, essa visão deu origem à teoria do patrimônio de AUBRY ET RAU, ${ }^{11}$ para a qual o patrimônio é constituído pelo conjunto dos direitos subjetivos de um indivíduo. Ou seja, sendo a pessoa tomada exclusivamente desde o ponto de vista da teoria da relação jurídica, ela é o seu patrimônio. Portanto, toda e qualquer restrição à propriedade é uma restrição à liberdade individual mesma, enquanto que a única esfera de desenvolvimento da personalidade que tem alguma relevância jurídica é a da acumulação econômica. Não se pode pensar em maior "coisificação" da pessoa.

A superação dessa concepção começará a desenvolver-se a partir de fins do sé. culo XIX, com a criação, por GIERKE, da teoria da personalidade. ${ }^{12} \mathrm{Tal}$ teoria surge como resposta a dois fenômenos sociais do final de século. $\mathrm{Na}$ esfera patrimonial, desenvolvimento da sociedade industrial fazia com que se tornasse necessário um questionamento do dogma autonomia da vontade, com o Estado passando a intervir pesadamente no campo da livre iniciativa econômica e contratual. De outro lado, o surgimento dos direitos sociais ou de crédi- 
to e a formação das democracias de massa impunha que, paralelamente à igualitarização, fosse resguardado aos indivíduos uma esfera de liberdade privada que pudesse manter-se a salvo da regulação estatal e da estandardização da sociedade. Para ORLANDO DE CARVALHO, ${ }^{13}$ tratava-se de assegurar ao homem, para que seja uma verdadeira pessoa, condições essenciais do seu "ser" e "dever ser", do seu livre desenvolvimento como ser humano. Para isso, surgia a teoria da personalidade, como um anseio de tutela jurídica da esfera do "humano" no homem: a sua intimidade, privacidade, honra ou saúde. Conforme HANNAH ARENDT, ${ }^{14}$ via-se emergir, paralelamente à esfera social, que une as esferas pública e privada, uma esfera da personalidade, que garante aquilo que de exclusivo traz em si cada ser humano.

Embora anterior à elaboração do Código Civil alemão, a teoria da personalidade vai ter acolhimento, nas codificações, apenas pelo Código Civil suíço de 1907 . O seu desenvolvimento legislativo se dará fundamentalmente através das constituições e declarações de direitos, das quais é exemplificativa a Declaração Universal dos Direitos do Homem da ONU, que consagrou a dignidade da pessoa humana como princípio fundamental. ${ }^{15}$

Para ORLANDO DE CARVA. $\mathrm{LHO},{ }^{16}$ são três os aspectos fundamentais dos direitos de personalidade: a essencialidade, a indissolubilidade e a ilimitabilidade, uma vez que o homem natural é, por si mesmo, ilimitado. Assim sendo, a questão mais importante, no que tange aos direitos de personalidade, é a de seu livre desenvolvimento e sua tutela. Daí a importância que, contemporaneamente, vêm dando os constitucionalistas à proteção do livre desenvolvimento da personalidade. CANOTILHO ${ }^{17}$ considera como estando subsumidos nesse princípio: a afirmação da integridade física e espiritual do homem como dimensão irrenunciável de sua individualidade autonomamente responsável; a libertação da angústia da existência, quer através do direito de estar só consigo mesmo, quer de mecanismos de socialidade, dentre os quais encontram-se o direito a condições mínimas de subsistência e o direito ao trabalho; a garantia e a defesa da autonomia individual; e a igualdade formal.

Conseqüentemente, pode-se afirmar que, hoje, a doutrina do livre desenvolvimento da personalidade possibilitou a redescoberta do homem como valor-fonte e finalidade do ordenamento jurídico como um todo, numa perspectiva que sobrepõe valores humanistas ao individualismo proprietário do século XIX.

Pode-se, porém, afirmar que prevalecia, em toda a dogmática civilística

13. Cl. CARVALHO, Orlando de. Les droits de lhomme dans le Droit civil portugais, pp. 9 e ss.

14. Apud LAFER, Celso. Op. cit., pp. 267 e ss.

15. Sobre as relaçoes entre os direitos de personalidade e o princípio da dignidade da pessoa humana, estendi-me mais longamente em meu artigo Dignidade da pessoa humana, conceito fundamental do Direito civil.

16. Cf. CARVALHO, Orlando de. Op. cit., loc. cit.

17. Cf. CANOTILHO, J. J. Gomes. Direito constitucional, p. 363.

Revista da Faculdade de Direito da UFRGS, v. 18, 2000

oitocentista, a assim chamada "lógica proprietária"? É o que me proponho a questionar, a partir da demonstração do quanto de inovador tem o Esboço de TEIXEIRA DE FREITAS a esse respeito.

\section{II - 0 caráter inovador de Teixeira de Freitas: a preservação do "humano" na pessoa}

Em sua obra de sistematizador, e, em um segundo momento, de codificador, são notoriamente reconhecidas em TEIXEIRA DE FREITAS duas grandes influências pessoais: LEIBNIZ e SAVIGNY. Do primeiro, teria ele herdado a concepção de necessidade da sistematização científica e da construção do Código a partir de uma Parte Geral e de uma Especial; ${ }^{18}$ enquanto o segundo seria a sua grande inspiração dogmática, em especial quando da elaboração daquele "único dispositivo" que é capaz de determinar todo o sistema: a bipartição dos direitos entre pessoais e reais. Quanto a este último aspecto, recebe nosso jurista a influência indireta da Metafísica dos costumes de KANT, ${ }^{19}$ da qual SAVIGNY é caudatário.

Construindo o seu sistema sobre a partição dos direitos entre pessoais e reais, a tábua de matérias da Consolidação das Leis Civis foi composta de uma Parte Geral, subdividida em pessoas e bens, à qual, no Esboço, foram acrescidos os fatos jurídicos; e uma Especial, versando sobre direitos pes-

8. Ver, a esse respeito, MARTINS-COSTA, Judith Hofmeister. O sistema na codificação brasileira: de Leibniz a Teixeira de Freitas. 19. Na edição francesa, pp. 69-75.

20. Cf. TEIXEIRA DE FREITAS, Augusto. Esboço, nota ao art. 17. soais e reais, e, no Esboço, sobre as disposições comuns a ambos os direitos. Conseqüentemente, a chave para o sistema de TEIXEIRA DE FREITAS é o seu conceito de pessoa.

No art. 16 do Esboço, estão definidas "pessoas" como sendo "todos os entes sus. cetíveis de aquisição de direitos". A esse artigo, completa o de $\mathrm{n}^{\mathrm{0}} 17$, que dispõe sobre a única classificação que admite das pessoas: "as pessoas, ou são de existência visível, ou de existência tão-somente ideal. Elas podem adquirir os direitos, que o presente Código regula, nos casos, e pelo modo, e forma, que no mesmo se determinar. Daí dimana sua capacidade, e incapacidade civil". Essa classificação, nova à época, reflefilosoficamente inovadora frente à dogmática civilística de então.

Em primeiro lugar, opta TEIXEIRA DE FREITAS pela utilização de um termo semanticamente associado à metafísica para considerar todas as pessoas como "entes". ${ }^{20}$ Dessa forma, demonstra repúdio pelas concepções então vigentes, como a de TOULLIER, que via a possibilidade de existência de diferentes tipos de pessoas de acordo com a situação e o estado, colocando-as todas em absoluta posição de igualdade sob a categoria metafísica do "ente". O repúdio às demais classificações propostas pela doutrina francesa, que separavam as pessoas em físicas e jurídicas, ou individuais e coletivas, denota uma segunda tomada de posite, igualmente, uma concepção 
ção filosófica. Para TEIXEIRA DE FREITAS, classificar as pessoas como físicas desnatura o homem, reduzindo-o ao seu aspecto animal em detrimento do espiritual, sem o qual "não seria ente jurídico, porque não seria suscetível de adquirir direitos", ao mesmo tempo que classificálas, desde uma ótica individualista, de individuais e coletivas, não explica o fenômeno das "pessoas de existência ideal" que também são pessoas individuais.

Reflexo mais importante do pensamento próprio de TEIXEIRA DE FREITAS sobre a teoria das pessoas é a crítica feita, na nota ao art. 21 do Esboço, à doutrina alemã, especialmente a SAVIGNY, no que tange à identificação de "pessoa" com "capacidade jurídica". Para o nosso jurista, su por que "pessoa" seja o mesmo que "capacidade jurídica" leva a supor, igualmente, ser possível a existência de seres humanos - que, por sua existência visível são naturalmente pessoas - que não sejam dotadas de capacidade de direito, o que leva ao reconhecimento da teoria romana do status individual e da capitis deminutio. Mes mo escrevendo um Código para uma sociedade escravagista, ressalta TEIXEIRA DE FREITAS que até os escravos são pessoas, uma vez que seres humanos: "por muitas que sejam as restrições, ainda lhes fica a aptidão para adquirir direitos; e tanto basta para que sejam pessoas". Daí a crítica igualmente endereçada, na nota ao art. 17 , a DEMOLOMBE, para o qual não se podia distinguir com exatidão entre pessoa, esta-

do e capacidade. Para TEIXEIRA DE FREITAS, só se pode indagar, ou não, de capacidade de direito em relação às "pessoas de existência ideal", uma vez que todos os seres humanos são pessoas, ainda que para estes varie a capacidade civil, que é sempre de fato, e não de direito, em virtude de sua dependência familiar. Desde um ponto de vista humanista, assume um repúdio "a tantas classificações inúteis de pessoas nos livros de Direito Civil".

Não sendo essa, no entanto, a concepção prevalente em sua época, sequer daquele que TEIXEIRA DE FREITAS considerava como sendo o seu maior mestre e influência pessoal, SAVIGNY, a qual designava como "o Jurisconsulto", qual poderia ter sido a influência recebida por nosso jurista para a formação de uma concepção humanista, tão inovadora e na contra-corrente do individualismo possessivo de sua época? Para REALE, ${ }^{21}$ isso denota a ainda pouco estudada influência do krausismo, em especial através de seu grande divulgador, HEINRICH AHRENS, sobre a obra de TEIXEIRA DE FREITAS. KRAUSE propunha-se a superar o individualismo kantiano, construindo uma dimensão social do Direito, que não poderia restar submetido à subjetividade transcendental, mas condicionado socialmente, uma vez que, sem o homem, não existe Direito que possa ser abstratamente considerado. Esse posicionamento efetivamente pode ser depreendido da obra legislativa de TEIXEIRA DE FREITAS, e sua teoria das

21. Cf. REALE, Miguel. Humanismo e realismo juridicos de Teixeira de Freitas.

pessoas é, indubitavelmente, um dos maiores reflexos. ${ }^{22}$

Posto isso, resta saber até que ponto pode-se considerar ter sido TEIXEIRA DE FREITAS, quando da confecção de sua teoria das pessoas, um precursor da contemporânea teoria humanista da personalidade. Pessoalmente, acredito ser o sistema do Esboço, em si, uma resposta afirmativa a essa questão.

O Livro Segundo da Parte Especial do Esboço é subdividido em três seções: a primeira versa sobre os direitos pessoais em geral, a segunda sobre os direitos pessoais nas relações de família, enquanto a terceira é destinada aos direitos pessoais nas relações civis. Temos, aqui, um reflexo da mesma lógica sistemática que deu origem à bipartição em Parte Geral e Especial, uma vez que há uma seção reservada às disposições comuns a ambas as sortes de direitos pessoais. Há, também, uma conseqüência direta da classificação das pessoas em "de existência visível" e "de existência ideal". Os direitos pessoais nas relações de família, dizendo respeito apenas às "pessoas de existência visível", são regulados em separado dos direitos pessoais nas relações civis, que podem referir-se tanto às pessoas "de existência visível" quanto às tão-somente "de existência ideal". Não tendo atingido o ideal sistemático do Projeto do novo Código $\mathrm{Ci}$ vil, que traz a bipartição do Direito de Família em pessoal e patrimonial, resguardou TEIXEIRA DE FREITAS, entretanto, e contrario sensu as demais codificações de sua época, um espaço próprio em seu sistema para a regulação dos direitos e deveres pessoais do homem naturalmente considerado: as relações familiares, ou seja, direitos de personalidade constituintes de sua vida privada.

Nesse aspecto, TEIXEIRA DE FREITAS, que não conhecia - nem poderia conhecer, uma vez que ainda não havia sido desenvolvida - a teoria da personalidade, demonstra, em sua sistemática, uma notável preocupação com o resguardo do humano na pessoa, operando em uma lógica totalmente inversa à prevalente na dogmática civilística oitocentista, obcecada pelas relações patrimoniais.

\section{Conclusões}

Sendo indiscutível a influência sofrida por TEIXEIRA DE FREITAS, através de SAVIGNY, do individualismo kantiano, essa não é absoluta, e, especialmente no que tange à teoria das pessoas, deve ser relativizada.

A influência de outras concepções filosóficas, em especial do krausismo e de AHRENS, conforme demonstra REALE, foram determinantes para que TEIXEIRA DE FREITAS buscasse uma concepção de Direito muito menos individualista ao mesmo tempo que inovadoramente humanista frente às demais codificações de sua época. Embora considerado por BEVILÁQUA um

22. A influência de AHRENS sobre a concepção nacional de "pessoa" no Direito é tão forte que mesmo BEVILÁQUA, Clóvis em seu Em defeza do Projecto do Codigo Civil brazileiro, apesar de não ser um seguidor dessa teoria, cita o autor para defender a Parte Geral do Projeto de Código Civil de 1899. Ver, a esse respeito, CUNHA, Alexandre dos Santos, A reforma do ensino jurídico e 0 processo codificatório civil: a independência do Direito brasileiro. 
jurista sem considerações filosóficas ${ }^{23}$ propôs ele, em virtude de suas convicções éti cas, um Código bastante mais avançado que o de 1916, que, embora confeccionado após o desenvolvimento da teoria da personalidade, não escapou de ser um reflexo, nas palavras de ORLANDO GOMES, ${ }^{24}$ de uma tríade extremamente conservadora: patriarcalismo, patrimonialismo e responsabilização.

\section{Bibliografia}

ALVES, Gláucia Corrêa Retamozo Barcellos. Do nominalismo ao direito moderno: uma leitura de Michel Villey. UFRGS/PPGD, Disciplina de Teoria Geral do Direito. Porto Alegre, 1999, monografia.

AUBRY ET RAU. Traité de Droit Civil français d'après la méthode de Zachariae. Tomo IX.

BEVILÁQUA, Clóvis. Em defeza do Projecto do Codigo Civil brasileiro. Rio de Janeiro, Fran cisco Alves, 1906.

Linhas e perfis jurídicos. Rio de Janeiro: Freitas Bastos, 1930.

CANOTILHO, J. J. Gomes. Direito constitucional. Coimbra (Portugal): Almedina, 1993.

CARVALHO, Orlando de. "Les droits de l'homme dans le Droit civil portugais". In Boletim da Faculdade de Direito da Universidade de Coimbra, no XLIX (1973).

CORRÊA DE OLIVEIRA, José Lamartine. "A teoria das pessoas no Esboço de Teixeira de Freitas: superação e permanência". In SCHIPANI, Sandro, org. Teixeira de Freitas ed il Diritto latinoamericano. Pádua (Itália) CEDAM, 1988.

CUNHA, Alexandre dos Santos. A reforma do ensino jurídico e o processo codificatório civil: a independencia do Direito brasileiro. UFRGS PPGD, Disciplina de Fundamentos do Direito Privado. Porto Alegre, 2000, monografia.

"Dignidade da pessoa humana, conceito fundamental do Direito civil". In MARTINS-COSTA, Judith Hofmeister. A reconstrução do Direito privado. São Paulo, RT, no prelo.

GOMES, Orlando. "Raízes históricas e sociológicas do Código Civil brasileiro". In Revista da AJURIS, no 9 (1979)

HATTENHAUER, Hans. Conceptos fundamentales del Derecho civil (tradução de Pablo Salvador Coderch). Barcelona (Espanha): Ariel, 1987.

KANT, Immanuel. Métaphysique des moeurs (tradução de Alain Renaut). Paris (França): GFFlammarion, 1994. 2 volumes.

LAFER, Celso. A reconstrução dos direitos humanos: um diálogo com o pensamento de Hannah Arendt. São Paulo: Companhia das Letras, 1998.

LARENZ, Karl. Derecho justo: fundamentos de ética jurídica (tradução de Luis Díez-Picazo). Madri (Espanha): Civitas, 1993

LOCKE, John. Two treatises of government. Cambridge (Reino Unido): Cambridge University Press, 1988.

MARTINS-COSTA, Judith Hofmeister. "O sistema na codificação civil brasileira: de Leibniz a Teixeira de Freitas". Comunicação apresentada ao VI Congresso Brasileiro de Filosofia. São Paulo, 1999. datilografado.

MESSINETTI, Davide. "Personalità (diritti della)". In Enciclopedia Giuridica Giuffrè. Milão (Itália): Giuffrè, 1984, verbete.

OPPETIT, Bruno. Philosophie du Droit. Paris (França): Dalloz, 1999.

REALE, Miguel. "Humanismo e realismo jurídicos de Teixeira de Freitas". In SCHIPANI, Sandro, org. Teixeira de Freitas ed il Diritto latinoamericano. Pádua (Itália): CEDAM, 1988.

TEIXEIRA DE FREITAS, Augusto. Consolida ção das Leis Civis. Rio de Janeiro: Garnier, 1883.

. Código Civil - Esboço. Brasília, EdUnB/ Ministério da Justiça, 1983. 2 volumes.

VILLEY, Michel. "La genèse du droit subjectif chez Guillaume d'Occam". In Archives de Philosophie du Droit, $\mathrm{n}^{\mathrm{9}} 9$ (1964).

23. Vide a biografia de TEIXEIRA DE FREITAS escrita por CLÓVIS BEVILÁQUA em seu Linhas e periis juridicos.

24. Cf. GOMES, Orlando. Raízes históricas e sociológicas do Código Civil brasileiro. 